\title{
MENURUNKAN KERUSAKAN YANG TIDAK TERJADWAL (UNSCHEDULE BREAKDOWN) SISTEM BAHAN BAKAR PADA UNIT KOMATSU HD 1500-7 DIPT UT SITE KALIMANTAN TIMUR
}

\author{
Vuko A.T. Manurung ${ }^{1, a}$,Yohanes Trijoko ${ }^{2, b}$, Randy Putra Afani ${ }^{3, c}$ \\ ${ }^{1}$ Program Studi Mesin Otomotif Politeknik Manufaktur Astra, Indonesia \\ ${ }^{2}$ Program Studi Teknik Mesin Manufaktur Politeknik Manufaktur Astra, Indonesia \\ avuko.manurung@polman.astra.ac.id, ${ }^{\mathrm{b}}$ yohanes.trijoko@polman.astra.ac.id, \\ crandyputrafan@gmail.com
}

\begin{abstract}
Abstrak.
Penelitian ini membahas mengenai modifikasi sistem bahan bakar pada unit Komatsu HD 1500-7, yang bertujuan untuk meningkatkan PA (physical avaibility) dan membuat downtime unit menjadi lebih cepat. Dasar dari penelitian ini dilakukan karena seringnya penggantian filter bahan bakar akibat tersumbatnya aliran bahan bakar sehingga biaya perbaikan dan akibat dari tidak beroperasinya unit tersebut menjadi tinggi. Proses perbaikan ini menggunakan Komponen utama berupa program Arduino Mega 2560, Lampu LED, LCD monitor dan Sensor. Prinsip kerja dari perbaikan (improvement) ini adalah alat tersebut bekerja sama untuk meneruskan sinyal voltage dari sensor menuju arduino, lalu sinyal tersebut akan diubah menjadi data berupa tulisan pada LCD. Lampu LED berfungsi sebagai warning lamp dan speaker yang ada di kabin berfungsi sebagai suara pengingat (warning sound). Hasil dari pembuatan sistem modifikasi ini adalah dapat ditentukan waktu yang tepat untuk mengganti filter bahan bakar sebelum terjadi kebuntuan dan mengakibatkan unit mati mendadak.
\end{abstract}

Kata kunci. sistem bahan bakar, Physical Avaibility, Downtime.

\begin{abstract}
.
This study discusses the modification of the fuel system in the Komatsu HD 1500-7 unit, which aims to improve PA (physical avaibility) and make unit downtime faster. The basis of this research was carried out because of the frequent replacement of fuel filters due to clogged fuel flow so that the cost of repairs and the consequences of not operating the unit became high. This repair process uses the main components in the form of Arduino Mega 2560 program, LED lights, LCD monitors and sensors. The working principle of this improvement is that the tool works together to forward the voltage signal from the sensor to Arduino, then the signal will be converted into writing data on the LCD. The LED light functions as a warning lamp and the speaker in the cabin functions as a warning sound. The result of making this modification system is that it can be determined the right time to replace the fuel filter before a deadlock occurs and cause the unit to die suddenly.
\end{abstract}

Keywords. fuel system, Physical Avaibility, Downtime.

\section{PENDAHULUAN}

Banyaknya jumlah unit yang ditangani PT UT di area pertambangan daerah Kalimantan Timur, menuntut kesiapan performa dari segi peralatan, tenaga kerja, sampai ketersediaan suku cadang selama 24 jam. Dengan adanya Full Maintenance Contract (FMC) terhadap semua unit yang digunakan oleh pengelola tambang, maka diperlukan kinerja yang baik dalam merawat dan menjaga agar semua unit yang di kontrak kerjakan berjalan sesuai dengan yang diharapkan. Schadule breakdown disesuaikan dengan buku manual unit dan pengaturannya menjadi bagian dari kontrak perawatan unit tersebut ${ }^{[1,2]}$. 
Komatsu jenis HD 1500-7 dari data dilapangan menunjukkan tingginya Down Time khususnya yang disebabkan oleh sistem bahan bakar (Fuel System). Kualitas bahan bakar sangat mempengaruhi banyaknya downtime karena bahan bakar sisa dari injector bercampur dengan oli dan kembali ke tanki dan juga adanya kotoran lain seperti gram besi dan kotoran yang tersaring di fuel filter. Adanya bahan-bahan lain ini menyebabkan terjadinya clogging di fuel filter yang kemudian akan membuat unit Low Power.

Beberapa menelitian terkait dengan sistem bahan bakar (fuel system, fuel filter) telah dilakukan untuk meningkatkan PA (Physical Availability) dan mengurangi kerusakan yang tidak terjadwal (unschadule breakdown) dari unit Komatsu yang beroperasi di area pertambangan dimana PT UT sebagai pemegang FMC (Full Maintenance Contract) ${ }^{[3,4]}$. Pada penelitian ini yang menjadi fokus adalah unit HD 1500-7. Tabel 1, adalah dana populasi unit HD (Heavy Duty Dump Truck).

Tabel 1. Populasi Unit Komatsu tipe HD

\begin{tabular}{|l|l|l|l|}
\hline No & Type Unit & Quantity & Unit Code \\
\hline 1 & HD 785-7 & 20 & DT 4031-4050 \\
\hline 2 & HD 1500-7 & 10 & DT $1051-1060$ \\
\hline
\end{tabular}

Keterangan : HD = Heavy Duty Dump Truck

tabel 2, menunjukkan frekuensi Unscheduled Breakdown pada unit HD 1500-7. Dari gambar tersebut terlihat adanya peningkatan frekuensi Unscheduled Breakdown pada bulan Agustus sampai dengan Oktober 2016 yaitu dari 10x Unscheduled Breakdown menjadi 16x Unscheduled Breakdown. Peningkatan Unscheduled Breakdown ini karena banyaknya Fuel Filter yang harus diganti sebelum waktu penggantian yang dianjurkan oleh Shop Manual ${ }^{[1]}$.

Tabel 2. Troubleshooting Record ${ }^{[5,6]}$

\begin{tabular}{|c|c|c|c|c|c|c|c|c|c|c|c|c|}
\hline \multicolumn{13}{|c|}{ IIT Maintenance REPORT HD150C } \\
\hline \multirow{3}{*}{ No } & \multicolumn{3}{|c|}{ As of 2016} & \multicolumn{5}{|c|}{ UCM REPORT } & \multirow{3}{*}{ Component } & \multirow{3}{*}{ Sub Comp } & \multirow{3}{*}{ cause Prob } & \\
\hline & C/Unit & $\mathrm{S} / \mathrm{N}$ & HM & Date & \multicolumn{3}{|c|}{ Responsible UT } & \multirow[t]{2}{*}{ UCM } & & & & \\
\hline & & Do & Ready & & T/Down & $\mathrm{T} / \mathrm{Up}$ & Dur & & & & & \\
\hline$=$ & 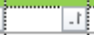 & $=$ & $=$ & $=$ & $=$ & $=$ & $=$ &. $\mathrm{T}$ & $=$ & $=$ & $=$ & \\
\hline 42 & DT1057 & A30076 & 37,844 & 16 Jun 16 & $08: 52$ & $15: 06$ & 6.23 & UCM & Engine & Fuel Filter & Leak & Replace Fuel Filter \\
\hline 175 & DT1060 & A30083 & 36,617 & 20 Aug 16 & $06: 30$ & 09:01 & 2.52 & UCM & Engine & Fuel Filter & Clogged & Replace Fuel Filter \\
\hline 181 & DT1054 & A30065 & 38,629 & 23 Aug 16 & $03: 26$ & $05: 52$ & 2.43 & UCM & Engine & & & Replace Fuel filter, Trouble shooting EIG \\
\hline 187 & DT1053, & A30057 & 39,117 & 25 Aug 16 & $13: 27$ & $14: 22$ & 0.92 & UCM & Engine & Fuel PUMP & Leaking & Repair Fuel Pump Actuator \\
\hline 188 & DT1056 & $A 30071$ & 39,456 & 26 Aug 16 & $7: 23$ & $9: 21$ & 1.97 & UCM & Engine & Fuel Filter & Clogged & Replace fuel filter \\
\hline 192 & DT1054 & A30065 & 38,694 & 28 Aug 16 & $6: 30$ & $8: 19$ & 1.82 & UCM & Engine & Prelube & Abnormal & Check \& Replace Fuel filter \\
\hline 195 & DT1059 & A30082 & 38,587 & 28 Aug 16 & $1: 53$ & $4: 17$ & 2.40 & UCM & Engine & Fuel Filter & Clogged & Replace Fuel Filter \\
\hline 197 & DT1059 & A30082 & 38,589 & 29 Aug 16 & $6: 57$ & $9: 30$ & 2.55 & UCM & Engine & Actuator & problem & Replace fuel actuator engine LH \\
\hline 200 & DT1059 & A30082 & 38,601 & 30 Aug 16 & $9: 28$ & $12: 37$ & 3.15 & UCM & Engine & Sensor & Abnormal & Replace fuel Pump pressure sensor \\
\hline 207 & DT1057 & A30076 & 38,866 & 31 Aug 16 & $22: 08$ & $23: 57$ & 1.82 & UCM & Engine & Fuel Filter & Broken & Replace Fuel Filter \\
\hline 211 & QT1053 & A30057 & 39,200 & $1 \operatorname{Sep} 16$ & $6: 30$ & $9: 55$ & 3.42 & UCM & Engine & Related & Error & Replace Fuel Filter \& Replace Fuel Pump Actuator \\
\hline 224 & QT1059 & A30082 & 38,682 & $5 \operatorname{Sep} 16$ & $8: 15$ & $3: 55$ & 19.67 & UCM & Engine & $\mathrm{ECM}$ & Broken & Trouble shotting engine low power, Replace Fuel Filter \\
\hline 230 & DT1056 & A30071 & 30,633 & $7 \operatorname{Sep} 16$ & $8: 15$ & $9: 40$ & 1.42 & UCM & Engine & Fuel Filter & Kotor & Replace Fuel Filter 3 PCS + PPM \\
\hline 235 & DT1060 & A30083 & 36,916 & $9 \operatorname{Sep} 16$ & $9: 05$ & $11: 07$ & 2.03 & UCM & Engine & Fuel Filter & Kotor & Replace Fuel Filter 3 PCS \\
\hline 239 & QT1055 & A30066 & 40,090 & $10 S_{e p} 16$ & $06: 38$ & $10: 54$ & 4.27 & UCM & Engine & Related & Low Power & Replace Fuel Filter \\
\hline 250 & DT1054 & A30065 & 38,913 & $12 S e p 16$ & $17: 55$ & $21: 15$ & 3.33 & UCM & Engine & Fuel Filter & Clogged & Replace Fuel Filter \\
\hline 257 & DT1053 & A30057 & 39,352 & $13 \mathrm{Sep} 16$ & 08:00 & $10: 00$ & 2.00 & UCM & Engine & Fuel Filter & Kotor & Replace Fuel Filter \\
\hline 277 & DT1059: & $A 30082$ & 38,781 & $16 \operatorname{Sep} 16$ & $14: 33$ & $18: 00$ & 3.45 & UCM & Engine & Electric & Short & Replace fuel filter \\
\hline 295 & DT1052 & A30056 & 38,907 & $20 \operatorname{Sep} 16$ & $10: 37$ & $16: 33$ & 5.93 & UCM & Engine & Engine System & Abnormal & Trouble shotting engine, Replace fuel filter \\
\hline 302 & DT1058: & $A 30077$ & 37,974 & $21 \operatorname{Sep} 16$ & $11: 10$ & $15: 45$ & 4.58 & UCM & Engine & Fuel System & Dirty & CleanFuel Line \& Bleeding Fuel System \\
\hline 318 & DT1052 & A30056 & 38,975 & 30 Sep 16 & $21: 40$ & $04: 23$ & 6.72 & UCM & Electrical & Electric & Short & Check Error + Grount test \\
\hline
\end{tabular}




\section{METODOLOGI PENELITIAN}

Untuk menemukan solusi dari permasalahan yang terjadi maka digunakan suatu alat pencari penyebab suatu masalah yaitu dengan menggunakan diagram tulang ikan (fishbone diagram $)^{[5-7]}$ seperti pada gambar 2 . Metode ini sudah lazim digunakan di PT UT untuk mencari akar masalah dan sekaligus solusinya. Dengan demikian terjadi proses perbaikan (improvement) yang terus menerus dan berkelanjutan. Alat ini meninjau persoalan dari sisi manusia, mesin, metode dan lingkungannya sehingga akar persoalan di tinjau secara komprihensif. Dengan demikian solusi yang diperoleh dan di aplikasikan juga akan menyelesaikan persoalan secara menyeluruh.

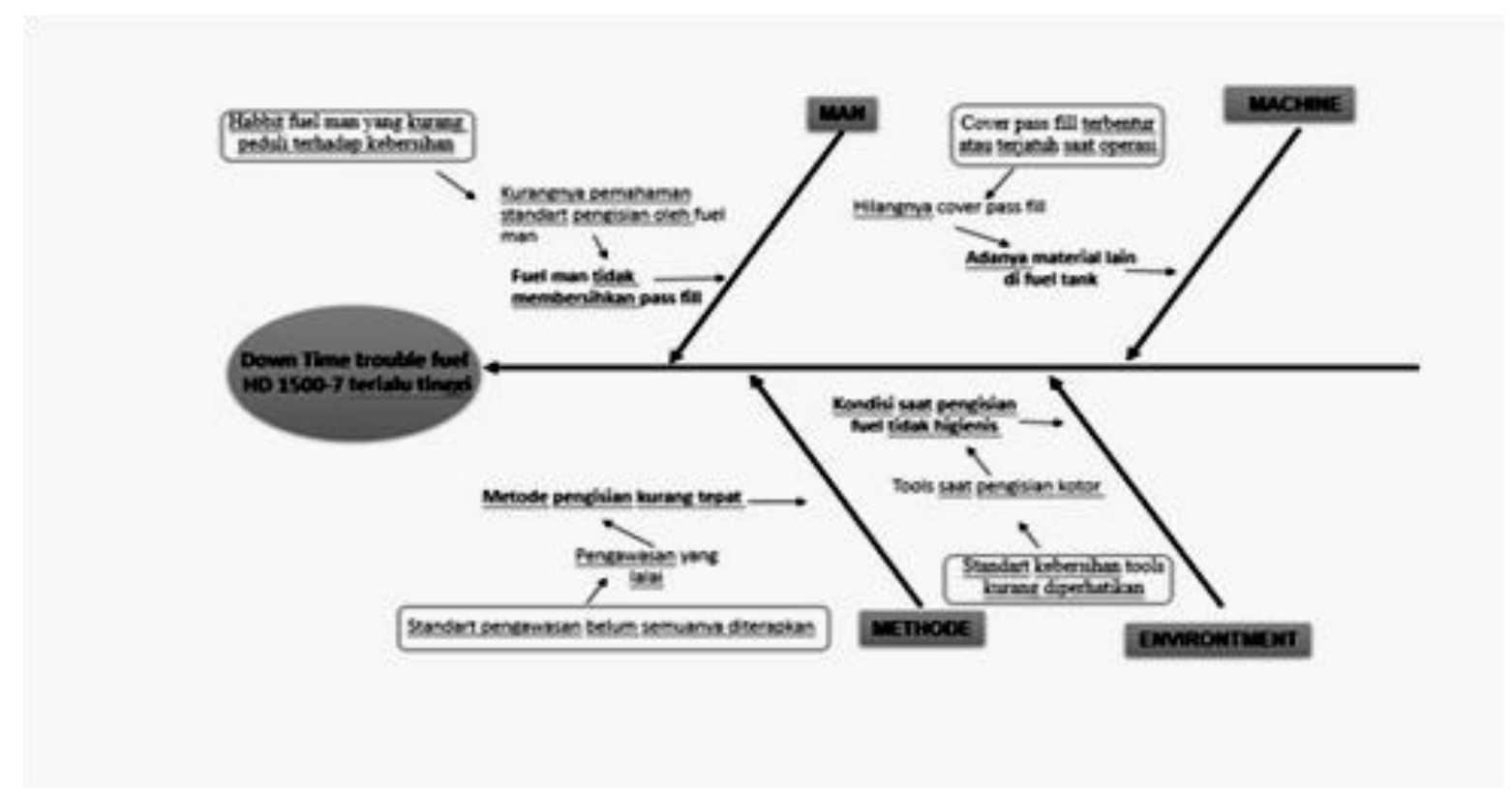

Gambar 2. Diagram tulang ikan

Pada sektor manusia (man) terdapat beberapa masalah terkait dengan kesadaran akan pentingnya kebersihan komponen saat akan mengisi fuel pada refueling area. Hal ini akan memicu tingginya tingkat kontaminan dalam fuel sehingga akan menyebabkan unit menjadi Breakdown.

Pada sektor mesin (machine) terdapat beberapa masalah terkait dengan kerusakan komponen penutup pada pass fill di fuel tank. Hal ini memicu banyaknya kontaminan yang akan masuk ke dalam fuel tank yang akan mengakibatkan adanya endapan kontaminan di dasar fuel tank.

Pada sektor metode (methode) terdapat masalah pada pemberlakuan SOP saat melakukan refueling di refueling area. Fuel man belum melakukan semua SOP pada saat pengisian fuel sehingga ada kontaminan yang melekat pada pass fill. Hal ini menyebabkan kontaminan tadi dapat ikut masuk ke sistem pada saat pengisian fuel.

Pada sektor lingkungan (environtment) terdapat keadaan yang sangat memungkinkan bagi fuel untuk terkontaminasi, yaitu tempat pengisian dan kondisi rerueling area berada di lapangan terbuka sehingga memungkinkan komponen unit dan alat untuk pengisian terkontaminasi oleh debu dll.

\section{HASIL, PEMBAHASAN DAN ANALISA}

Berdasarkan diagram tulang ikan maka solusi yang ditawarkan adalah sebagai berikut:

a. Manusia (People)

Pada sektor manusia, implementasi akan menggunakan metode sharing in class. Implementasi yang akan dilakukan adalah sosialisasi mengenai "Kebersihan pengisian bahan bakar". Sosialisasi ini 
bertujuan untuk meningkatkan pengetahuan mekanik dan fuel man mengenai tahap pengisian bahan bakar yang benar di Refueling area. Materi yang disampaikan didapatkan dari standar "pengecekan kebersihan pengisian dan tools". Pengimplementasiannya sudah di diskusikan dengan Supervisior dan Quality Assurance.

b. Mesin (Machine)

Dalam sektor ini penulis akan mengganti coupler di supply pump menjadi sensor transmitter agar dapat mendeteksi kebuntuan. Penulis juga akan membuat sebuah rangkaian detector yang akan bekerja beriringan dengan sensor. Jadi ketika pressure fuel berada di bawah range normal maka detector akan memberikan warning kepada operator.

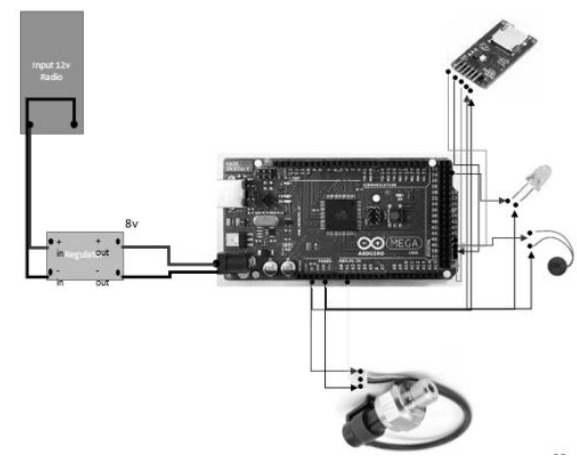

Gambar 4. Clogging Detector

c. Metode (Methode)

Pada sektor metode, implementasi yang akan di jalankan adalah cross check tata cara pengisian fuel yang benar. Metode yang digunakan adalah diskusi dan observasi lapangan mengenai tahapan tahapan saat pengisian fuel. Penulis melakukan observasi lapangan dengan mengikuti kegiatan daily inspection ke unit HD 1500-7 dan melakukan riset kepada fuel man mengenai tata cara pengisian fuel yang benar. Tidak ada modifikasi aturan saat pengisian fuel karena aturan yang ada dinilai sudah memenuhi standart pengisian yang benar.
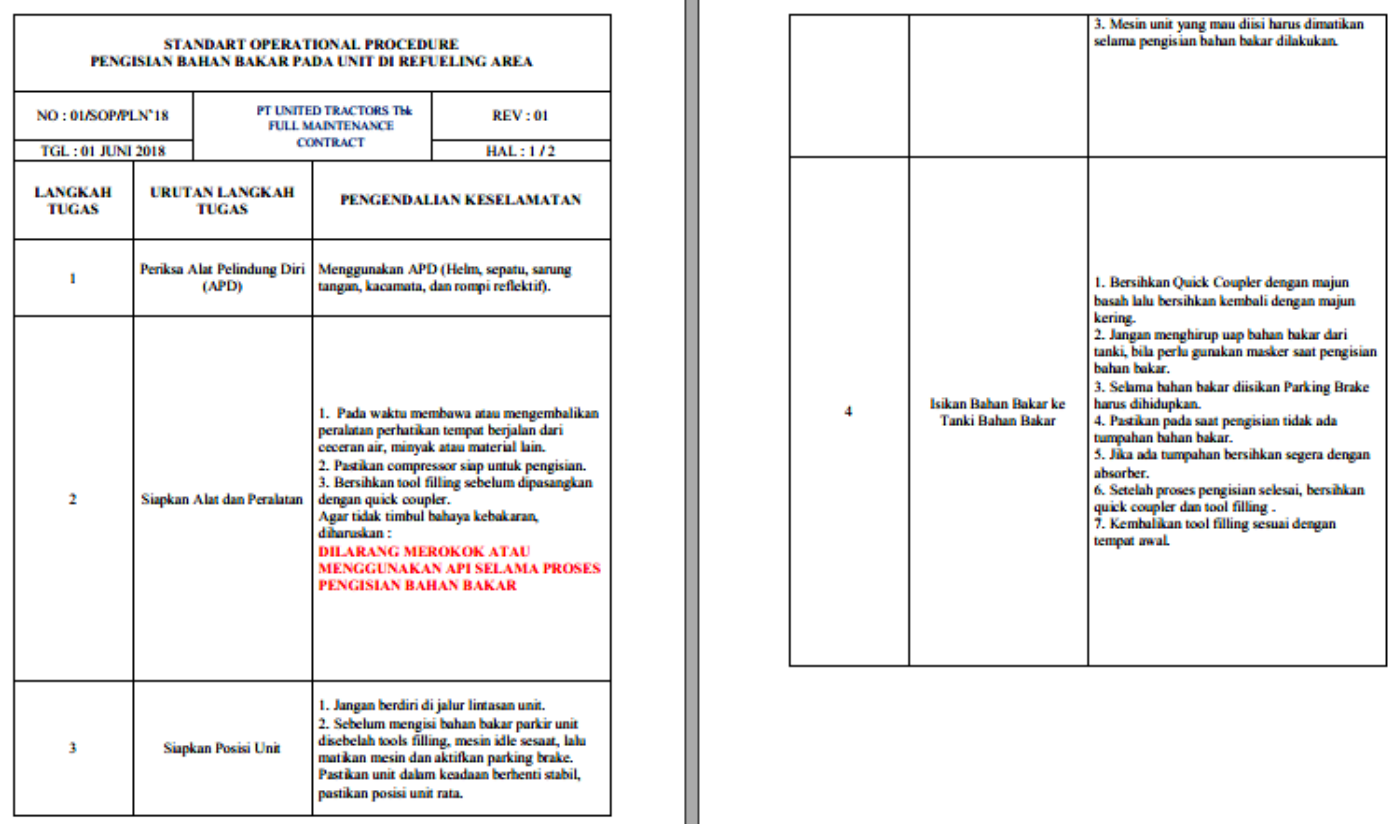

Gambar 5. SOP pengisian fuel 


\section{d. Lingkungan (Environtment)}

Pada sektor lingkungan, implementasi yang akan dilakukan adalah membersihkan alat pengisian fuel sebelum dan sesudah mengisi fuel di refueling area. Sehingga dapat mengurangi kemungkinan masuknya benda asing kedalam sistem bahan bakar.

\section{Manfaat}

Manfaat yang diperoleh dari penelitian ini adalah PA (Physical Availability) yang meningkat yang diikuti dengan biaya (cost) yang dapat dihemat dalam operasional unit karena proses pergantian suku cadang yang sesuai dengan schadule dari buku manual. Disamping itu keuntungan lainnya adalah image dari perusahaan di mata pemberi kontrak kerja. Dengan demikian unit akan beroperasi secara maksimal dan efisian.

Biaya yang dapat dihemat ini kemudian di konversikan kedalam bentuk NQI (Net Quality Income) berupa potensi keuntungan selama 1 tahun. Perhitungan tersebut adalah sebagai berikut:

$$
\begin{array}{ll}
\text { - } \quad \text { Ritase unit/jam } & =\text { USD } 56.01 \\
\text { - } \quad \text { Populasi unit } & =10 \mathrm{unit} \\
\text { - } \quad \text { Downtime UCM } & =125 \mathrm{jam}
\end{array}
$$

a. Biaya Penggantian Fuel Filter

- Harga 1 Fuel Filter HD 1500-7 = USD 24.47

- 1 unit HD 1500-7 ada 3 pcs fuel filter = USD $24.47 \times 3=$ USD 73.41

- $\quad$ Filter Clogging per unit $=$ USD $73.41 \times 25$ (trouble/annum) $=$ USD 1,835.25, maka untuk 10 unit adalah $=$ USD $1,835.25 \times 10 \quad=$ USD 18,352.5

- Bila 1 USD = Rp. 14.303,00, maka total biaya penggantian fuel filter: USD 18,352.5 x Rp. 14.303,00= = Rp. 262.495.808,00

b. Biaya downtime yang dapat di hemat per unit $=$ Ritase unit $\mathrm{x}$ jumlah downtime $=$ USD 56.10/hours x 125 hours = USD 7,001.25. Dengan demikian untuk 10 unit biaya downtime adalah: USD 7,001.25 x $10=$ USD 70,012.5. Dalam rupiah $=$ USD 70,012.5 x Rp. 14.303,00= Rp. 1.001.388.790,00

c. Harga pembuatan alat adalah $=\mathrm{Rp} 1.500 .000,00$

Dari perhitungan diatas maka NQI dari sistem yang dibuat adalah:

Harga Penggantian Filter + biaya downtime - Harga Pembuatan Alat adalah $=$ Rp 262.495.808,00 + Rp. 1.001.388.790,00. - Rp 1.500.000,00 = Rp 1.262.384.598,00

\section{KESIMPULAN}

Dari penelitian ini diperoleh bahwa potensi penghematan terhadap perusahaan (NQI) sebesar Rp. 1.262.384.000,00. Disamping itu juga memberikan kesadaran terhadap kebersihan saat proses pengisian fuel dan image perusahaan menjadi lebih baik.

\section{DAFTAR PUSTAKA}

1. Komatsu Ltd. (2010). Shop Manual Komatsu HD 1500-7, Komatsu Ltd. Japan.

2. Komatsu Ltd. (2009). Specifications \& Application Handbook Edition 30. Komatsu Ltd Japan.

3. Vuko AT Manurung, Erwin Setiawan (2018) Meningkatkan Efisiensi Anggaran Maintenance di PT United Tractors Area FMC SIMS Site Batukajang-Kaltim Studi Kasus Saringan Udara (Air Filter), Technologic vol.8 Politeknik Manufaktur Astra.

4. VAT Manurung, RI Poetra (2018) Auto Drain Valve Water Separator inside the Unit of Komatsu HD 465-7R, OP Conference Series: Materials Science and Engineering, vol. 306 IOP Publishing.

5. https://www.cms.gov/medicare/provider-enrollment-and 
certification/qapi/downloads/fishbonerevised.pdf.

6. https://www.researchgate.net/publication/46567642_Application_Of_Fishbone_Diagram_To_ Determine_The_Risk_Of_An_Event_With_Multiple_Causes.

7. https://www.researchgate.net/publication/46567642_Application_Of_Fishbone_Diagram_To_ Determine_The_Risk_Of_An_Event_With_Multiple_Causes

8. Unit Maintenance Record (2016) HD 1500-7 . PT. United Tractors FMC PAMA Area Site Batukajang.

9. Unit Maintenance Record (2017) HD 1500-7. PT. United Tractors FMC PAMA Area Site Batukajang.

10. Unit Maintenance Record (2018) HD 1500-7. PT. United Tractors FMC PAMA Area Site Batukajang.

11. Huzij, Robert, Angelo Spano, SeanBennett (2009) Heavy Equipment System, Delmar

12. Gilles, Tim (2012) Automotive Service Inspection, Maintenance, Repair, 4th Edition, Delmar.

13. https://www.smsequip.com/assets/documents/equipment/mining/mechanical-trucks/hd15007.pdf

14. http://www.komatsu.com.br/portal/wp-content/uploads/2014/05/HD1500-7-AESS727-00.pdf

15. Anggraini, L. (2018). ANALISA STRUKTUR MIKRO PADA PROSES FIRING DALAM FABRIKASI WELDED BEAM DENGAN BAHAN SM490YB. Prosiding Seminar Nasional Pakar (pp. 363-367). 